\title{
Physicochemical Comparison between Glass Surface and Zinc Oxide Surface: Study of Microbial Adhesion
}

\author{
Youssef NAJIH ${ }^{1}$, Mustapha ADAR ${ }^{1}$, Noureddine KOUIDER ${ }^{1}$, Jamaa BENOURRAM $^{1}$ and \\ Mustapha MABROUKI ${ }^{1}$
}

${ }^{1}$ Industrial Engineering Laboratory

Sultan Moulay Slimane University, Faculty of Science and Technology

PO Box 523, Beni Mellal Morocco

\begin{abstract}
The general context of this work is to study the effect of physicochemical properties on bacterial adhesion. In this case, the adhesion of Staphylococcus aureus (gram-positive bacteria) has been studied on a thin layer of zinc oxide (ZnO). This layer was deposited on glass substrates by sputtering under different powers (150, 200 and 250 watts). The contact angle measurements were used to calculate the surface energy components of each substrate (dispersive and polar) and to define the hydrophilic/hydrophobic character by the calculation of the free energy of interaction. Analysis of adherent cells on the surface of each substrate was made by the atomic force microscope according to the time of suspension. The results showed that the glass surface has a large polar component; against the surface of the ZnO film has a significant dispersive component. This shows that the glass surface is governed by short-range forces (Lewis acid-bases forces) while ZnO film is governed by long-range forces (van der Waals forces). Images obtained by atomic force microscopy revealed that the $\mathrm{ZnO}$ layer has an antibacterial effect against $S$. aureus.
\end{abstract}

Key Words: Staphylococcus Aureus, Surface Energy, Atomic Force Microscopy, Zinc Oxide, Contact Angle.

\section{INTRODUCTION}

The relevance of contaminated surfaces in spreading pathogenic microorganisms to foods is already well established for food processing plants [1-2]. Some pathogenic bacteria are able to adhere to food-contact surfaces and remain viable even after cleaning and disinfection [3]. Staphylococcus aureus is among the most common pathogenic bacteria isolated from surfaces in food processing plants [4], where it can adhere and form biofilms [5]. Foodborne disease caused by S. aureus is typically intoxication due to the ingestion of enterotoxins preformed in food by enterotoxigenic strains [6].

Several substratum surface properties have been shown to influence bacterial adhesion. These properties include surface charge [7], topography [8], hydrophobicity [9], surface chemistry and surface energy [10-12]. The substratum surface properties could be altering with the presence of molecules [13-14], experimental conditions, roughness level and the coating by different composite. To contribute to the understanding of the phenomenon of adhesion, we determined the physicochemical properties of the solid surface. In our case we have prepared thin layers of zinc oxide $(\mathrm{ZnO})$ on glass slides by the cathode sputtering under different powers $(150,200$ and 250 watt).

$\mathrm{ZnO}$ is captivated because of inexpensive, non-toxicity, transparency and it is the most auspicious material for research, medical and industrial application. $\mathrm{ZnO}$ is a soft material with an approximate hardness of 5 GPa especially for the c-axis orientation growth and also has strong pyroelectric, piezoelectric and luminescence properties [15]. Because of these properties, $\mathrm{ZnO}$ thin films can be used in wide range of applications such as implants, biosensors, UV lasers, phosphor applications, solar cells and optoelectronics [16]. Several techniques are available for the deposition of ZnO, like, Sputtering [17], Plasma enhanced chemical vapor deposition [18], Sol-gel process [19], Spray pyrolysis [20], Electron beam evaporation [21] etc. Among these methods, magnetron sputtering is very effective because of high deposition rates, uniformity, easy fabrication, parameter controllability and film adhesion [22]. Deposition parameters, such as, substrate bias, etc. can significantly change the film properties [17], [23- 25]. ZnO nanoparticles can be used as food preservative because of its excellent antibacterial activity [26] and it can enhance the fluorescence signal for biomolecules detection like DNA [27]. Quantum dots of ZnO are used as quantitative labels for biological assays [28] and it has high isoelectric point which facilitates immobilization of biomolecules 
[29]. In the present work, $\mathrm{ZnO}$ thin films were deposited by sputtering on glass substrates under different power. The objective was to predict the adhesion of $\mathrm{S}$. aureus on glass substrates with a $\mathrm{ZnO}$ film. S. aureus was chosen as a model in this study because this bacterium is found in the food industry and the ability to adhere and colonize the inert surface. This colonization can cause problems of food contamination leading to the deterioration of the latter.

\section{MATERIAL AND METHODS}

\subsection{Microorganisms, culture conditions, and sample preparation}

The strain used as a model for this study was S. aureus ATCC 25923 Bacteria were incubated over night at $37^{\circ} \mathrm{C}$ in Luria Bertani medium containing the following (per liter of distilled water). Tryptone $10 \mathrm{~g}, 5 \mathrm{~g}$ of yeast extract and $10 \mathrm{~g} \mathrm{NaCl}$. After $24 \mathrm{~h}$ incubation, cells were harvested by centrifugation for $15 \mathrm{~min}$ at $8400 \mathrm{~g}$ and washed twice with and suspended in $0.1 \mathrm{M}$ of KNO3 solution. The physicochemical properties, including hydrophobicity and Lewis acid-base properties were evaluated by using the measurement of the angle of contact with the following solvents: water, Formamide, and Diiodomethane. S. aureus was hydrophilic $\left(\theta \mathrm{w}=26,45^{\circ} ; \gamma \mathrm{D}=28,7 \mathrm{~mJ} / \mathrm{m} 2\right)$, electron donor $(\gamma-=51.3 \mathrm{~mJ} / \mathrm{m} 2)$ and weakly electron acceptor $(\gamma+=2.4 \mathrm{~mJ} / \mathrm{m} 2)$.

\subsection{Preparation of thin films of zinc oxide}

$\mathrm{ZnO}$ thin films were prepared by reactive RF-sputtering in an ALCATEL SC451 deposition system equipped with an ALCATEL ARF $601 \mathrm{RF}$ generator operating at $13.56 \mathrm{MHz}$. These films were deposited using a high purity Zn metal target with a diameter of $10 \mathrm{~cm}$ in an argon oxygen gas mixture. Prior to the deposition, glass substrates were ultrasonically cleaned in acetone and isopropyl alcohol followed by deionized water to remove any impurities and then rinsed with deionized water. The substrates were then mounted at a distance of $10 \mathrm{~cm}$ above the $\mathrm{Zn}$ target $(5 \mathrm{~N}$ : purity, diameter: $10 \mathrm{~cm})$. The vacuum chamber was evacuated to a final pressure of $1.5^{*} 10^{6}$ mbar. The target was pre-sputtered for $10 \mathrm{~min}$, and the substrates were not intentionally heated during the deposition. The reactive sputtering was carried out in an Ar/O2 gas mixture with 30\% of O2. The films were deposited using an RF power of 150, 200 and $250 \mathrm{~W}$ for $30 \mathrm{~min}$. These parameters were obtained from a previous optimization of the deposition conditions. The sample was cut into $1 \mathrm{cmx} 1 \mathrm{~cm}$ coupons cleaned and rinsed with distilled water.

\subsection{Contact angle measurement}

The contact angle measurements were performed using a goniometer (GBX instruments, France) by the sessile drop method. This instrument is a standard goniometer with image analysis attachments (video camera, computer with monitor, and image analysis software). The sessile drop method for the contact angle determination was used through deposition of liquid drops on solid surfaces with a micrometer syringe and controlled by means of a camera. The contact angles were determined from the droplet image using the tangent method. At least contact angles of 5 droplets were measured for each solvent on three independently conditioned surfaces. The final values were averaged on at least three different locations on the surface. In our case we used three liquids of different polarities whose interfacial tensions are known, as shown in table 1.

Table.1. Values of the total free surface energy and its components as a result of interaction of $L W$ and ab used in the investigation of contact angle of liquids at a temperature of $20^{\circ} \mathrm{C}[\mathrm{mJ} / \mathrm{m} 2]$. Obtained from the refs [30]

\begin{tabular}{|c|c|c|c|c|c|}
\hline \multirow{2}{*}{ Liquid } & \multicolumn{5}{|c|}{ surface energy component $\left(\mathbf{m J} / \mathbf{m}^{2}\right)$} \\
\cline { 2 - 6 } & $\gamma_{L}$ & $\gamma_{L}^{\mathrm{LW}}$ & $\gamma_{L}^{\mathrm{AB}}$ & $\gamma_{L}^{+}$ & $\gamma_{L}^{-}$ \\
\hline Water & 72.8 & 21.8 & 51.0 & 25.5 & 25.5 \\
\hline Formamide & 58.0 & 39.0 & 19.0 & 2.28 & 39.6 \\
\hline Diiodomethane & 50.8 & 50.8 & $\approx 0$ & $\approx 0$ & $\approx 0$ \\
\hline
\end{tabular}

\subsection{Atomic force microscopy}

AFM is a scanning probe microscopy instrument that consists of a force-sensing cantilever, a piezoelectric canner, and a photodiode detector. The cantilever bends upwards due to repulsive forces, or downwards due to attractive forces, between a sample (e.g. a bacterium) and a small tip that is an integrated part of the end of the cantilever. The deflection of the cantilever is monitored by reflecting a laser off the top of the free-end of the cantilever and into the photo detector. In this work, the atomic force microscopy used was a Nano-surf Flex AFM digital instruments operated in the tapping mode. 


\subsection{Surface Energy (Young-Van OSS equation)}

Young's equation [31] is used to describe the interactions between the forces of cohesion and adhesion and measure what is referred to as surface energy. As first described by Thomas Young [1], the contact angle of a liquid drop on an ideal solid surface is defined by the mechanical equilibrium of the drop under the action of three interfacial tensions.

$$
\gamma_{S V}=\gamma_{S L}+\gamma_{L V} \cos \theta
$$

Where $\gamma_{L V}, \gamma_{S V}$, and $\gamma_{S L}$ represent the liquid-vapor, solid-vapor, and solid-liquid interfacial tensions, respectively, and $\theta$ is the contact angle. The surface free energy cannot be measured directly. Instead, the contact angle measurements with test liquid deposited onto the solid surface to calculate the surface energy is performed. Good approach, Van OSS and CHAUDHURY (acidbase theory) [32] is used in this study. The components of the surface energy of a surface $\left(\gamma_{s}^{+}, \gamma_{s}^{-}\right.$and $\left.\gamma_{s}^{\mathrm{LW}}\right)$ were determined by carrying out contact angle measurements using three probe liquids (one nonpolar and two polar) with known surface tension parameters $\left(\gamma_{s}^{+}, \gamma_{s}^{-}\right.$and $\left.\gamma_{s}^{\mathrm{LW}}\right)$ and using Young's equation:

$$
(\cos \theta+1) / 2=\left(\gamma_{S}^{\mathrm{LW}} \gamma_{L}^{\mathrm{LW}}\right)^{1 / 2} / \gamma_{L}+\left(\gamma_{S}^{+} \gamma_{L}^{-}\right)^{1 / 2} / \gamma_{L}+\left(\gamma_{S}^{-} \gamma_{L}^{+}\right)^{1 / 2} / \gamma_{L}(2)
$$

Where $\theta$ is the contact angle measured, $\gamma^{\mathrm{LW}}$ is the der Waals Van free energy component, $\gamma^{+}$is the electron acceptor component, $\gamma^{-}$component is the electron donor and the indexes (S) and (L) denote respectively solid surface and the liquid phase.

The surface free energy is expressed as: $\gamma_{s}=\gamma_{\mathrm{s}}^{\mathrm{LW}}+\gamma_{\mathrm{s}}^{\mathrm{AB}}$ (3)

Where $\gamma_{s}=\gamma_{\mathrm{s}}^{\mathrm{LW}}+\gamma_{\mathrm{S}}^{\mathrm{AB}}$ is the energy component without acid-base.

\subsection{Thermodynamic approach}

The Thermodynamic theory [33] is the second physicochemical approach that has been used to describe bacterial attachment to surfaces. It takes into account the various types of attractive and repulsive interactions, such as van der Waals, electrostatic or dipole but expresses them collectively in terms of free energy, a thermodynamic term. The approach requires estimation of numerical values of thermodynamic parameters, surface free energy of the bacterial and substratum surfaces and surface free energy (or surface tension) of the suspending solution, in order to calculate the Gibbs adhesion energy for bacterial adhesion.

Mathematically the free energy of adhesion $\Delta \mathrm{G}_{a d h}$ can be expressed by:

$$
\Delta \mathrm{G}_{a d h}=\gamma_{b s}-\gamma_{b l}-\gamma_{s l}(4)
$$

Where $\gamma$ represents interfacial free energies for different interfaces: bacteria-solid, bacteria liquid and solid liquid. Adhesion is energetically favored only if $\Delta \mathrm{G}_{a d h}$ is negative. For calculation of $\Delta \mathrm{G}_{a d h}$, the free energy of adhesion was divided into two parts: Lifshitz van der Waals component and acid-base component.

$$
\Delta \mathrm{G}_{a d h}=\Delta \mathrm{G}_{b l s}^{L W}+\Delta \mathrm{G}_{b l s}^{A B}(5)
$$

Calculation according to LW-AB approach using the Lifshitz -van der Waals dispersive and acid-base components of surface energies is following:

$$
\begin{gathered}
\Delta \mathrm{G}_{a d h}^{L W}=\left(\left(\gamma_{B}^{L W}\right)^{1 / 2}-\left(\gamma_{S}^{L W}\right)^{1 / 2}\right)^{2}-\left(\left(\gamma_{B}^{L W}\right)^{1 / 2}-\left(\gamma_{L}^{L W}\right)^{1 / 2}\right)^{2}-\left(\left(\gamma_{S}^{L W}\right)^{1 / 2}-\left(\gamma_{L}^{L W}\right)^{1 / 2}\right)^{2} \\
\Delta \mathrm{G}_{a d h}^{A B}=2\left[\left(\gamma_{L}^{+}\right)^{1 / 2}\left[\left(\gamma_{B}^{-}\right)^{1 / 2}+\left(\gamma_{S}^{-}\right)^{1 / 2}-\left(\gamma_{L}^{-}\right)^{1 / 2}\right]+\left(\gamma_{L}^{-}\right)^{1 / 2}\left[\left(\gamma_{B}^{+}\right)^{1 / 2}+\left(\gamma_{S}^{+}\right)^{1 / 2}-\left(\gamma_{L}^{+}\right)^{1 / 2}\right]-\left(\left(\gamma_{b}^{+} \gamma_{S}^{-}\right)^{1 / 2} \times\left(\gamma_{b}^{-} \gamma_{S}^{+}\right)^{1 / 2}\right]\right.
\end{gathered}
$$

\subsection{Hydrophobicity}

According to van Oss [34] the hydrophobicity of a given material (i) can be defined in terms of the variation of the free energy of interaction between two moieties of that material immersed in water $(w)$. The free energy comprises a polar (AB) and a non-polar $(\mathrm{LW})$ component and the variation of the total free energy is given by:

$$
\Delta \mathrm{G}_{i w i}=-2\left[\left(\left(\gamma_{i}^{L W}\right)^{1 / 2}-\left(\gamma_{i}^{L W}\right)^{1 / 2}\right)^{2}+2\left(\left(\gamma_{i}^{+} \gamma_{i}^{-}\right)^{1 / 2}+\left(\gamma_{w}^{+} \gamma_{w}^{-}\right)^{1 / 2}-\left(\gamma_{i}^{+} \gamma_{w}^{-}\right)^{1 / 2}-\left(\gamma_{w}^{+} \gamma_{i}^{-}\right)^{1 / 2}\right)\right](8)
$$

When the value of $\Delta \mathrm{G}_{i w i}$ tows is negative (the free energy of interaction between molecules is attractive) it means that the solid surface has less affinity for water than among themselves, meaning that they have a hydrophobic character. On the contrary, solid surface are hydrophilic when this value is positive $\left(\Delta \mathrm{G}_{i w i}>0\right)$.

\section{RESULTS AND DISCUSSION}

\subsection{Surface physic-chemical analyses}

The physicochemical characteristics of different $\mathrm{ZnO}$ substrates are calculated from the Young-van Oss equation. Table 2 summarizes the values of the surface energy components of each substrate (Lifshitz / van der Waals and acid / base component). The value of the surface energy varies between $45.21 \mathrm{~mJ} / \mathrm{m}^{2}$ and $40.7 \mathrm{~mJ} / \mathrm{m}^{2}$ for the $\mathrm{ZnO}$ films. To the glass surface the value of the surface energy was $50.1 \mathrm{~mJ} / \mathrm{m}^{2}$. The water contact angle values on the $\mathrm{ZnO}$ film substrates are above $65^{\circ}\left(\Theta_{\text {water, } \mathrm{ZnO}} 200 \mathrm{w}\right.$ $=78.4^{\circ}$ ) and the glass surface $\Theta$ water, glass $=34.2^{\circ}$. As described by Van Oss the free energy of interaction $\left(\Delta \mathrm{G}_{i w i}\right)$ is negative for the substrates of the $\mathrm{ZnO}$ film the degree of hydrophobicity varies between $\Delta \mathrm{G}_{i w i}=-36.61 \mathrm{~mJ} / \mathrm{m}^{2}$ and $\Delta \mathrm{G}_{i w i}=-44.97 \mathrm{~mJ} / \mathrm{m}^{2}$. The value of the free energy of interaction of the glass surface is positive $\Delta \mathrm{G}_{i w i}=22.48 \mathrm{~mJ} / \mathrm{m}^{2}$, as shown in Figure 3 . 
International Journal of Advances in Scientific Research and Engineering (ijasre), Vol 5 (3), March-2019

Table.2. Values of the contact angle and surface energy components $[\mathrm{mJ} / \mathrm{m} 2]$

\begin{tabular}{|c|c|c|c|c|c|c|c|c|c|}
\hline \multirow{2}{*}{ Substratum } & \multicolumn{3}{|c|}{ Contact angle } & \multicolumn{5}{c|}{ Surface energy component } & \multirow{2}{*}{} \\
\cline { 2 - 10 } & $\Theta_{\mathrm{W}}$ & $\Theta_{\mathrm{F}}$ & $\Theta_{\mathrm{D}}$ & $\gamma^{L W}$ & $\gamma^{+}$ & $\gamma^{-}$ & $\gamma^{A B}$ & $\gamma^{T o t}$ & $\Delta \mathrm{G}_{i w i}$ \\
\hline ZnO 150 w & 70 & 51,9 & 36,3 & 43 & 0,1 & 12,2 & 2,21 & 45,21 & $-36,61$ \\
\hline ZnO 200 w & 78.4 & 65 & 40,5 & 39,04 & 0,2 & 11 & 3,00 & 42,40 & $-37,08$ \\
\hline ZnO 250 w & 75.8 & 57,4 & 39,3 & 40 & 0,01 & 9,3 & 0,70 & 40,70 & $-44,97$ \\
\hline Glass & 34.2 & 31 & 29.3 & 32.7 & 1.9 & 45.3 & 18.5 & 50.1 & 22.48 \\
\hline
\end{tabular}

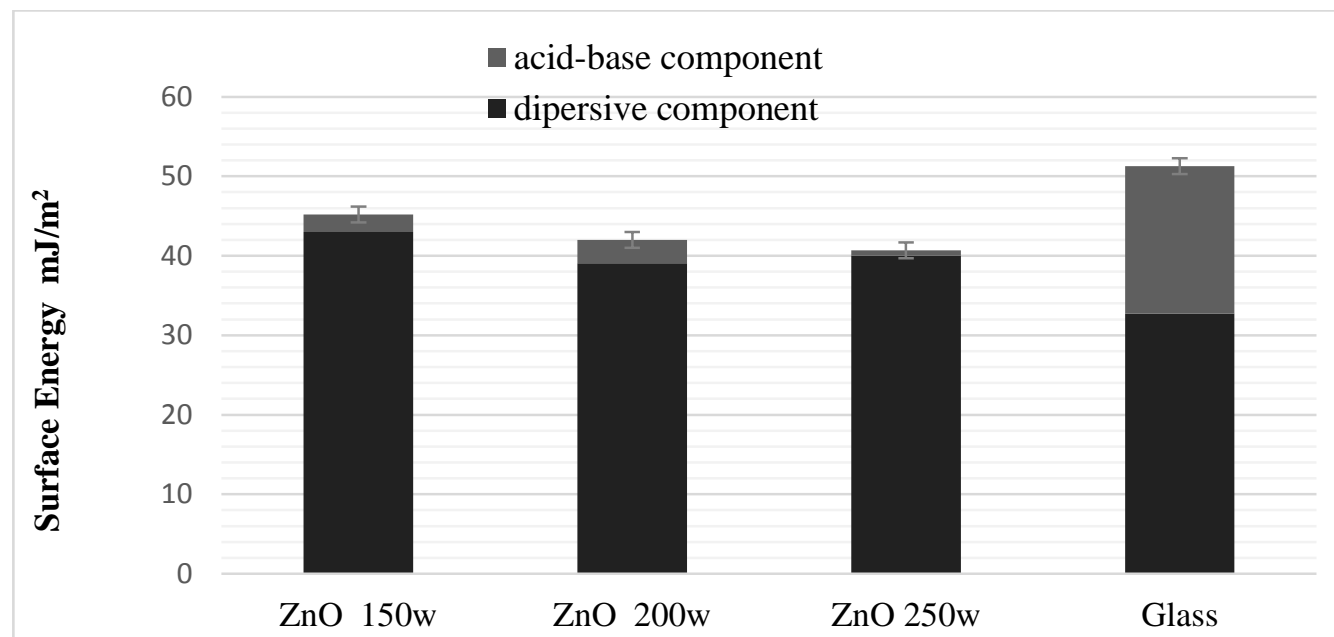

Figure 1: Components of the surface energy (Lifshitz Van der Waals / acid-base) for the glass and for the various substrates of the $\mathrm{ZnO}$ film $\left(\mathrm{mJ} / \mathrm{m}^{2}\right)$.

The difference between the glass surface and the $\mathrm{ZnO}$ film are observed in the acid-base interaction $\gamma \mathrm{AB}$ (acceptor and electron donor) as said polar component. The value of the acid-base component $\gamma^{\mathrm{AB}}=3.0 \mathrm{~mJ} / \mathrm{m} 2$ calculated for the film surface $\mathrm{ZnO} 200 \mathrm{w}$ is small compared to the value of this component to the glass surface $\left(\gamma^{\mathrm{AB}}=18.5 \mathrm{~mJ} / \mathrm{m} 2\right)$. On the other hand, the basic component of the glass surface is very important that the front surface of the film $\mathrm{ZnO}\left(\gamma^{-}(\right.$glasse $)=45.3 \mathrm{~mJ} / \mathrm{m}^{2} ; \gamma^{-}(\mathrm{ZnO} 150 \mathrm{w})=$ $12.2 \mathrm{~mJ} / \mathrm{m} 2$ ) which means the difference in the interaction donor / electron acceptor between the glass surface and the $\mathrm{ZnO}$ film. The dispersive component of surface energy to the various substrates is very large relative to the acid-base component. Values range between $\gamma^{\mathrm{D}}=39.04 \mathrm{~mJ} / \mathrm{m} 2$ and $\gamma^{\mathrm{D}}=43 \mathrm{~mJ} / \mathrm{m} 2$ for the $\mathrm{ZnO}$ film surfaces, and $\gamma^{\mathrm{D}}=32.7 \mathrm{~mJ} / \mathrm{m} 2$ to the glass surface.

The characteristics presented in Figures 1 and 2 summarize the results obtained. The difference between the glass surface and the surface of the $\mathrm{ZnO}$ film is observed. Acid-base component of glass has $36.2 \%$ of the surface energy. Against by the acidbase component of $\mathrm{ZnO}$ films shows only $4.89 \%, 7.08 \%$ and $1.71 \%$ respectively for $\mathrm{ZnO} 150 \mathrm{w}$, $\mathrm{ZnO} 200 \mathrm{w}$ and $\mathrm{ZnO} 250 \mathrm{w}$ of the surface energy.

Free energy of adhesion values of different substrates of $\mathrm{ZnO}$ film and glass are calculated using $\mathrm{LW}$ - $\mathrm{AB}$ approach and are shown in Table 3. The Lifshitz van der Waals component is attractive for all substratums, the aim acid / base component is repulsive, especially for glass surface. 


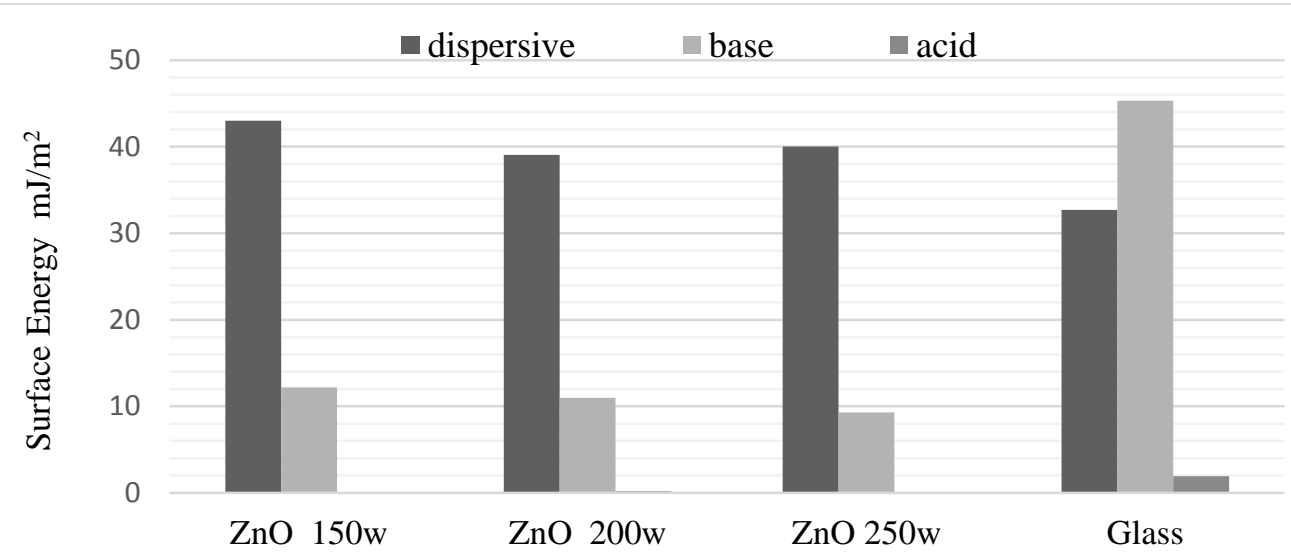

Figure 2: Components of the surface energy (dispersive component / acid component / basic component) for the glass and for the various substrates of the $\mathrm{ZnO}$ film $\left(\mathrm{mJ} / \mathrm{m}^{2}\right)$

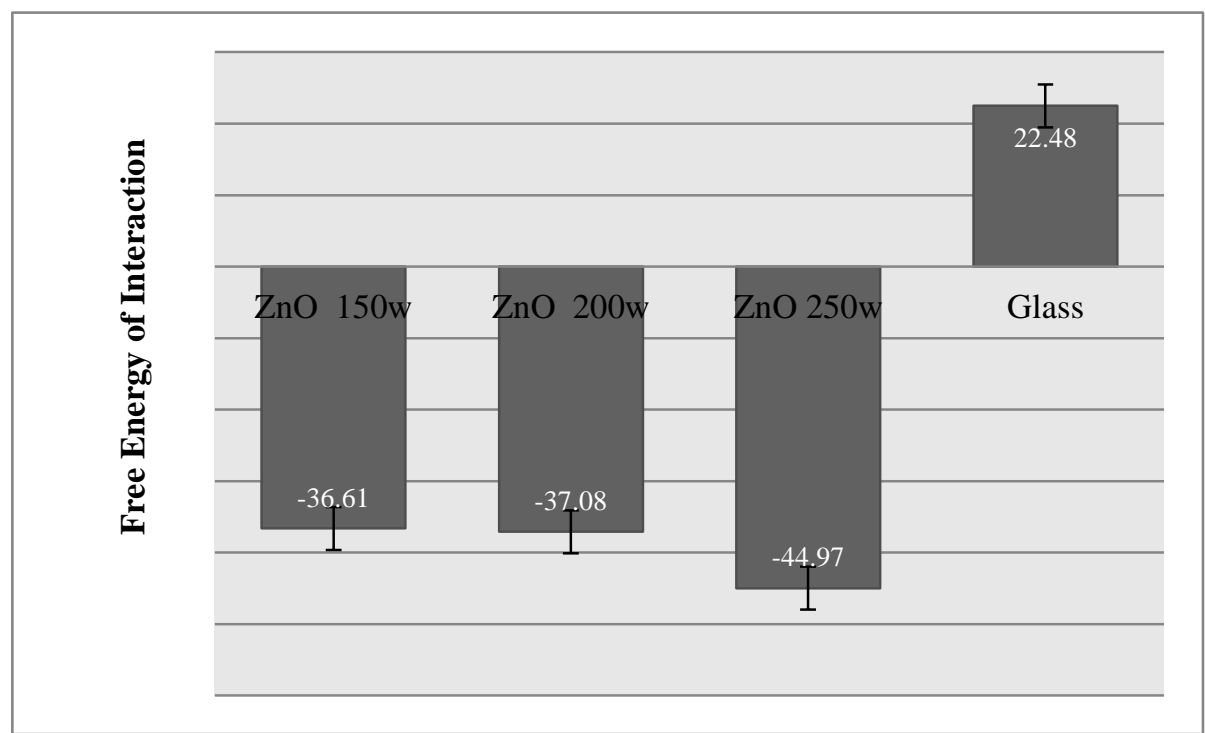

Figure 3: Hydrophobicity for the glass and for the various substrates of the $\mathrm{ZnO}$ film $(\mathrm{mJ} / \mathrm{m} 2)$

\subsection{Bacterial adhesion}

Staphylococcus aureus adhesion is characterized primarily by the calculation of the free energy of adhesion $\Delta \mathrm{G}_{a d h}$. As presented in Table 3 the values of this energy for surfaces of the thin film zinc oxide are lower than the value obtained from the glass surface. From the thermodynamic point of view, more the value of the free energy is important bacterial adhesion becomes favorable. This means that the surface of the thin film of zinc oxide disadvantage approximately the initial attachment of the $S$. aureus bacteria. On the opposite, the glass surface which may be a carrier supporting the initial attachment of this microorganism. The difference here is observed in the values of $\mathrm{AB}$ component of the free energy of adhesion, it is mentioned in Table 3 that the glass surface has a very high value $\Delta \mathrm{G}_{a d h}$ because the presence strong of short-range forces. Further, evaluating the number of adherent bacteria on surfaces of each substrate was investigated by atomic force microscopy.

The images obtained indicate the number of adherent cells on the substrate surfaces (glass and $\mathrm{ZnO}$ thin film). The figures (4A and 4B) show the evolution of adherent cells on the glass surface in the first two hours of suspension in order to characterize the initial attachment of the bacterial cell of $S$. aureus, also Figures (5A and 5B) show the evolution of these cells on the $\mathrm{ZnO}$ film as a function of time. By quantifying the adherent cells on the glass surface show a growth that evolves over time. On the other hand, the cells seem consistent with each other and they follow a specific path in its evolution. During the first hour of the suspension, the two surfaces (glass and $\mathrm{ZnO}$ film) have approximately the same number of adherent cells. The difference is measured during the second hour of suspension, and the structure of the bacterial colonies is different. The colonization on the glass is well organized and the cells follow a path as shown in Figures (4A and 4B). The cells were reduced on the surface of the $\mathrm{ZnO}$ film, they are inconsistent and they follow random directions as presented in the Figures (5A and 5B). Figure 6 summarizes the difference between the number of adherent cells on glass surface and the $\mathrm{ZnO}$ surface. 
International Journal of Advances in Scientific Research and Engineering (ijasre), Vol 5 (3), March-2019

Table.3. Free energy of adhesion and its components $\left[\mathrm{mJ} / \mathrm{m}^{2}\right]$

\begin{tabular}{|l|c|c|c|}
\hline Substratum & $\Delta \boldsymbol{G}_{\boldsymbol{a d h}}^{\boldsymbol{L W}}$ & $\Delta \boldsymbol{G}_{\boldsymbol{a d h}}^{\boldsymbol{A B}}$ & $\Delta \boldsymbol{G}_{\boldsymbol{a d h}}^{\boldsymbol{T o t}}$ \\
\hline ZnO 150w & $-2,60$ & 9,10 & 6,50 \\
\hline ZnO 200w & $-2,17$ & 7,31 & 5,14 \\
\hline ZnO 250w & $-2,28$ & 6,85 & 4,57 \\
\hline Glass & $-1,44$ & 27,28 & 25,84 \\
\hline
\end{tabular}

The bacterial adhesion is the result of physicochemical interactions between the cell and the solid phase. Many studies establish a relationship between the physicochemical properties of the surface free energy of interaction and cell adhesion phenomenon [35-36]. In this work, the effect of physicochemical properties on adherence of $S$. aureus was well observed. The thermodynamic approach was established for predicting the adherence phenomenon of $S$. aureus cells has been well verified by the quantification of adherent cells after analyzing images obtained by atomic force microscopy.

The results showed that the glass surface has a favorable environment for the growth of $S$. aureus colonies. This surface has an important polar component (acid-base) while the $\mathrm{ZnO}$ films have a low polar component. This means that the glass surface is governed by the short-range forces and the $\mathrm{ZnO}$ surface by the ling range forces. This shows the influence of acid-base interaction in the adhesion of the Gram-positive cells. In addition, the water contact angle measurements on the surfaces of $\mathrm{ZnO}$ films obtained at different powers show the hydrophobicity of this surface $\left(\Theta \mathrm{W}>65^{\circ}\right)$. Conversely, the glass surface is hydrophilic. This interpretation explains the role of hydrophobicity on adhesion of $S$. aureus. If the surface is hydrophilic, the adhesion of $S$. aureus is favored, and if the surface is hydrophobic, this adhesion is less favored.

This difference measures the anti-adhesive side of the zinc oxide films because, $\mathrm{ZnO}$ damage the bacterial cell wall by electrostatic interaction between $\mathrm{ZnO}$ and cell surfaces or the production of reactive oxygen species [37]. ZnO in particular has shown great promise in reducing infections due to its inherent antimicrobial properties. These properties have been proven to be enhanced when the particles are on the nanoscale rather than the microscale [38] While the mechanism of the observed antibacterial activity of $\mathrm{ZnO}$ is not completely understood, several studies have suggested two possible mechanisms: the production of increased levels of reactive oxygen species (ROS) such as hydroxyl radicals and singlet oxygen, and/or the accumulation of the nanoparticles in either the cytoplasm or the periplasmic region of the bacterial cells causing disruption and disorganization of cellular functions and membranes [39-40].
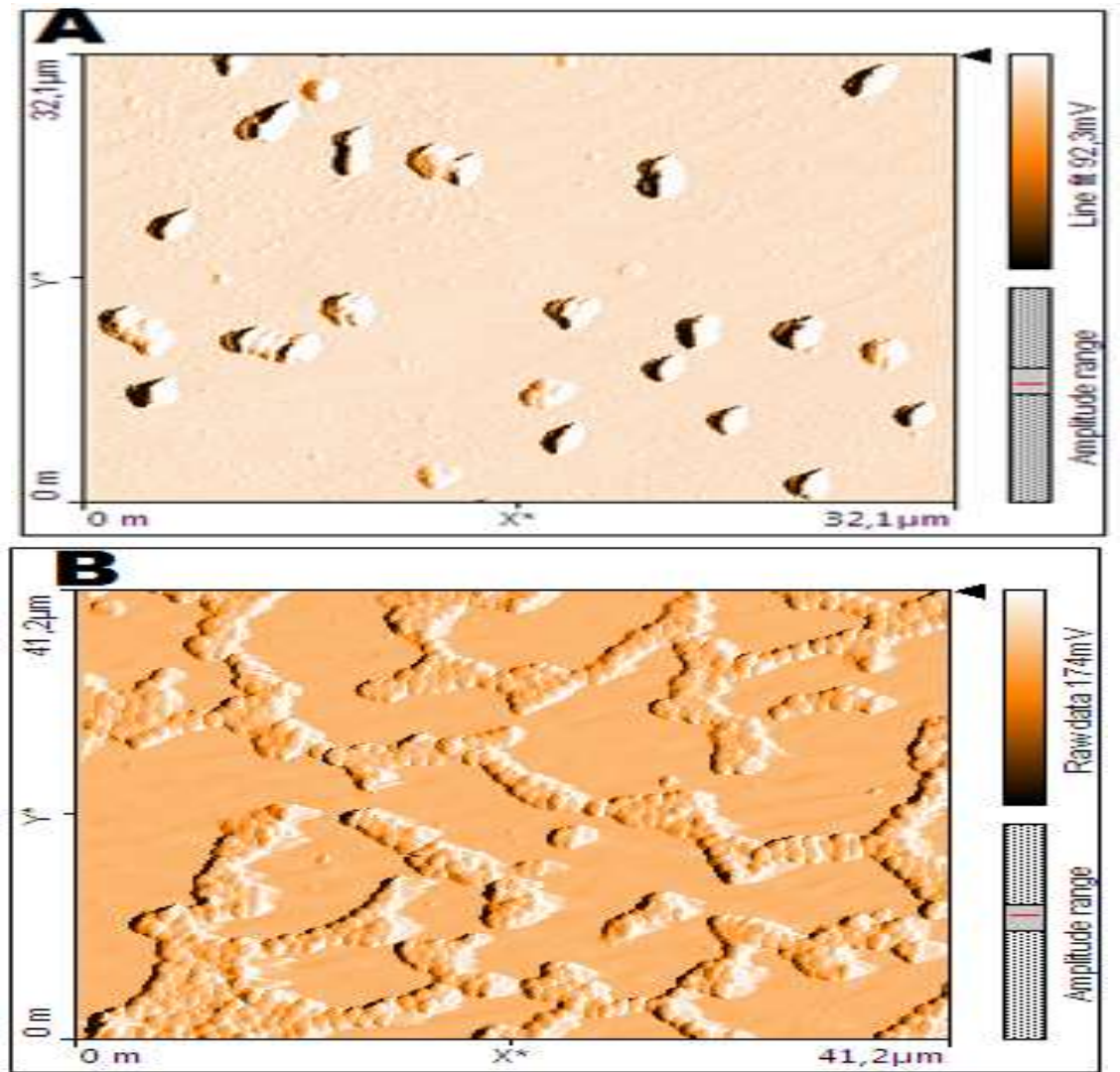

Figure 4: AFM 2D Topography, Images of Staphylococcus aureus ATCC 25923 on the glass surface, (A): 1 hour; (B): 2 hours 
International Journal of Advances in Scientific Research and Engineering (ijasre), Vol 5 (3), March-2019
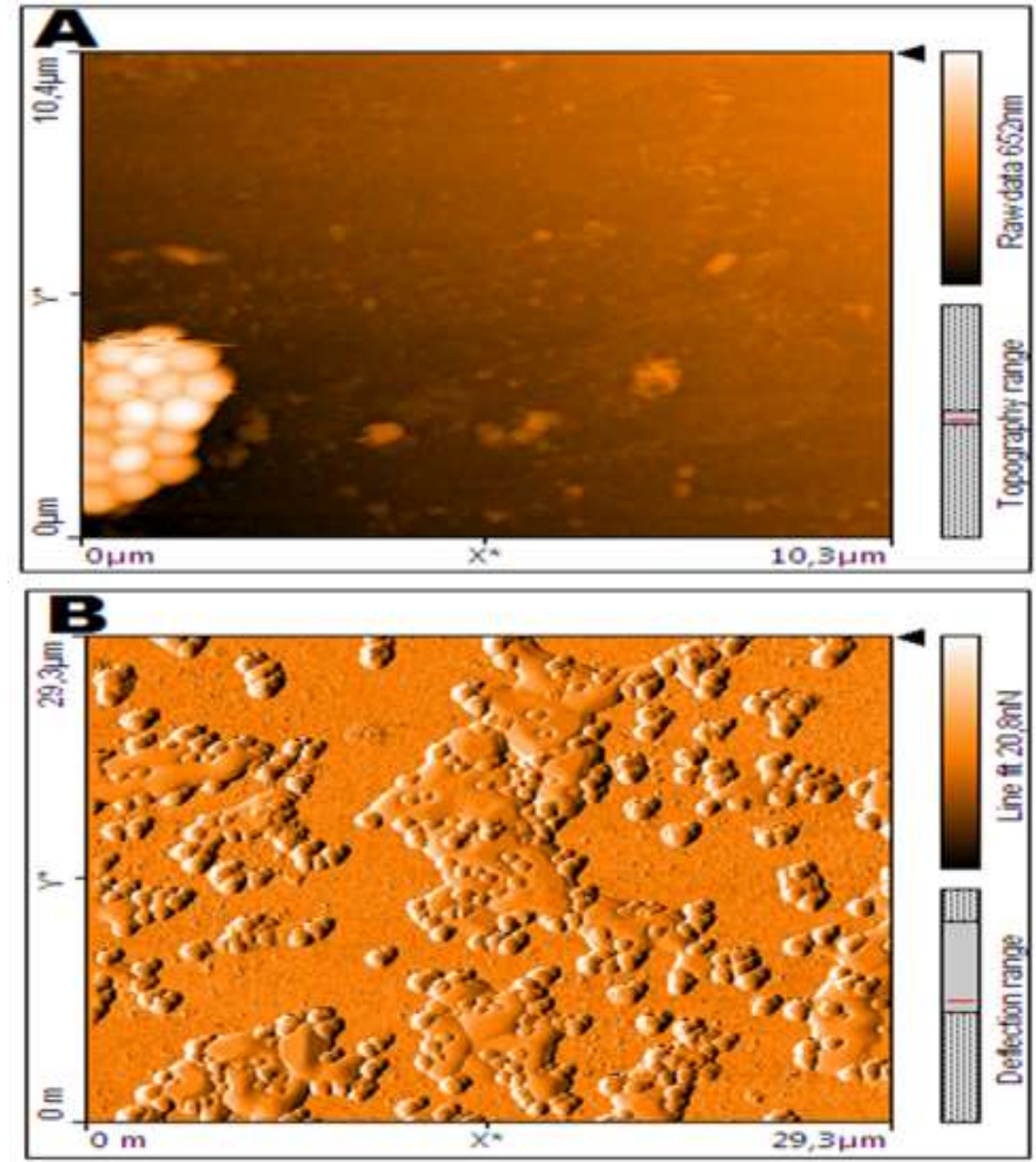

Figure 5: AFM 2D Topography, Images of Staphylococcus aureus ATCC 25923 on the ZnO surface, (A): 1 hour; (B): 2 hours

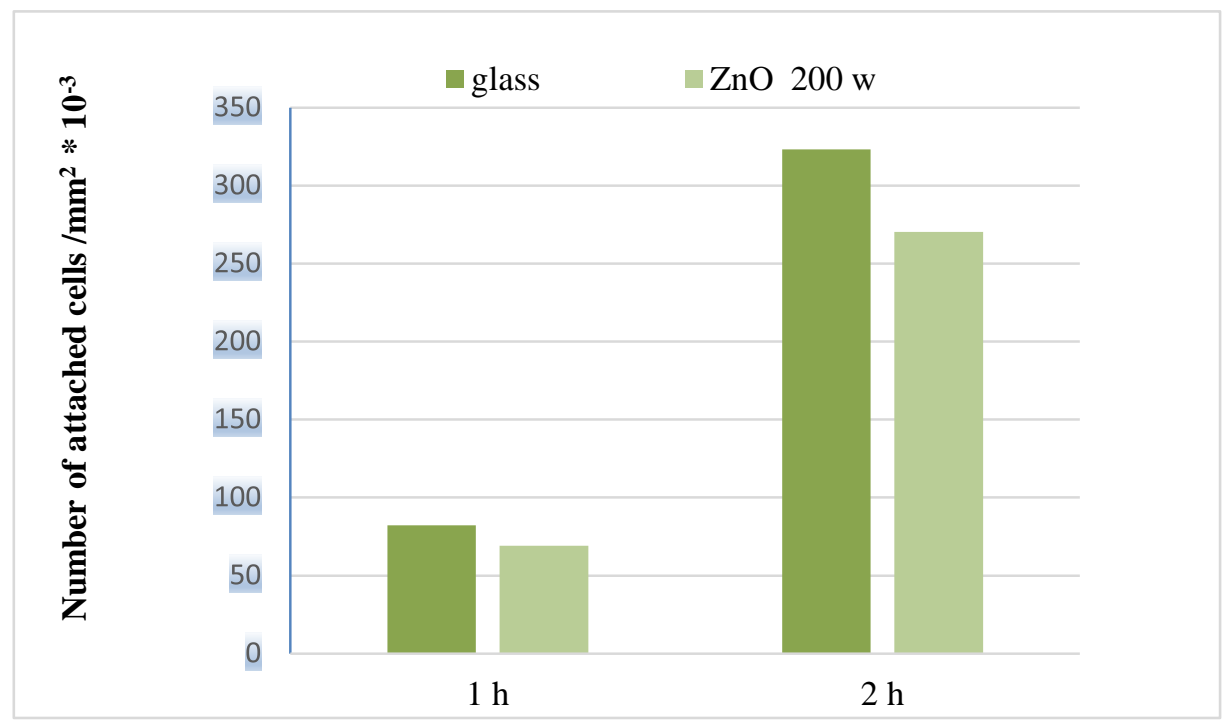

Figure 6: Number of attached cells on glass surface and on $\mathrm{ZnO}$ surface

\section{CONCLUSION}

$\mathrm{ZnO}$ thin films were deposited on glass substrate using sputtering, with different power values. The effect of physicochemical properties on the adhesion of Staphylococcus aureus has been well observed in this work. Analysis by atomic force microscopy showed a difference between S. aureus adhesion on the glass surface and on the surface of $\mathrm{ZnO}$ films. This shows that $\mathrm{ZnO}$ thin films has excellent anti adhesion activity against $\mathrm{S}$. aureus. 


\section{REFERENCES}

1. Kusumaningru, H.D.; Riboldi, G.; Hazeleger, W.C.; Beummer, R.R. Int. J. Food Microbiol., v.85, n.3, p.227-236, 2003.

2. Fuster-Valls, N.; Hernández-Herrero, M.; Marín-De-Mateo, M.; Rodríguez-Jerez, J.J. Food Control. , v.19, n.3, p.308-314, 2008.

3. Ammor, S.; Chevallier, I.; Lague, A.; Labadile, J.; Talon, R.; Dufour, E. Food Microbiol. , v.21, n.1, p.11-17, 2004.

4. Pastoriza, L.; Cabo, M.L.; Bernárdez, M.; Sampedro, G.; Herrera, J.R., v.215, n.3, p.189-193, 2002.

5. Kunigk, L.; Almeida, M.C.B. Braz. J. Microbiol. , v.32, n.1, p.38-41, 2001.

6. Normanno, G.; La Salandra, G.; Dambrosio,A.; Quaglia, N.C.; Corrente, M.; Parisi, A.; Santagada, G.; Firinu, A.; Cirsetti, E.; Celano, G.V. Int. J. Food Microbiol. , v.115, n.3, p.290-296, 2007.

7. G. Harkes, J. Feijen, J. Dankert, Biomaterials. 12 (1991) 853.

8. A.M. Gallardo-Moreno, M.L. Gonzalez-Martin, J.M. Bruque, C. Perez-Giraldo, Colloids Surf., A Physicochem. Eng. Asp. 249 (2004) 99.

9. Y. Liu, S.F. Yang, Y. Li, H. Xu, L. Qin, J.H. Tay, J. Biotechnol. 110 (2004) 251.

10. A.W.J. Van Pelt, A.H. Weerkamp, M.H.W.J.C. Uyen, H.J. Busscher, H.P. de Jong, J. Arends, Appl. Environ. Microbiol. 49 (1985) 1270.

11. A.G. Karakecili, M. Gumusderelioglu, J. Biomater, Sci. Polymer Edn. 13 (2002) 185.

12. Q. Zhao, C. Wang, Y. Liu, S. wang, Int. J. Adhes. Adhes. 27 (2007) 85.

13. E.M. Harnett, J. Alderman, T. Word, Colloids Surf., B Biointerfaces 55 (2006) 90.

14. M.E. Parent, D. Velegol, Colloids Surf., B Biointerfaces 39 (2004) 45.

15. Chennupati Jagadish and Stephen 1. Pearton, Zinc Oxide, Bulk, Thin fims and Nanostructures, Processing, Properties and Applications, Chapter 1, 1-20.

16. Anderson Janott an Chris G Van de Walle. Prog. Phys., vol.72 (2009) 126501 (29pp).

17. S. Flickyngerova, K. Shtereva, v. Stenova, D. Hasko, I. Novotny, V. Tvarozek, P. Sutta, E. Vavrinsky. Appl Surf Sci., vol. 254, pp. 3643-3647 2008.

18. K. Haga, M. Kamidaira, Y. Kashiwaba, T. Sekiguchi, H. Watanabe,". Crystal Growth., Vol. 214, pp. 77-80, Jun 2000.

19. M. Popa, R.A. Mereu, M. Filip, M. Gabor, T. Petrisor ,I., L. Ciontea, T. Petrisor, Materials Letters., Vol. 92, pp. 267-270, Feb 2013.

20. R. Ayouchi, F. Martin, D. Leinen, 1. R. Ramos-Barrado. Crystal growth. vol. 247, pp. 497-504, 2003.

21. ] Amjid Iqbal, Arshad Mahood, Taj Muhamad Khan Ejaz Ahmed. Materials International. , Vol. 23, pp. 64-69, Feb 2013.

22. K. Ellmer, "Magnetron sputtering of transparent conductive zinc oxide. Appl. Phys., Vol. 33 pp. R17, 2000.

23. Hong-Lei Ma, Xiao-Tao Hao , ln Ma, Ying-Ge Yang, Shu-Lai Huang, Feng Chen, Qing-Pu Wang, De-Heng Zhang. J. Surf Coat Technol., vol. 161 pp. 58-61, 2002.

24. K. Vijayalakshmi, K. Karthick, P. Dhivya and M. Sridharan. Ceramics International, Vol. 39, pp. 5681-5687, 2013.

25. X.C. Wang, X. M. Chen, B. H. Yan. J. Alloy Compd., vol. 488 pp. 232-237, 2009.

26. Yanping Xie, Yiping He, Peter L. Irwin, Tony Jin an Xianming Shi, J. Appl. Environ. Microbiol. , pp. $2325-2331,2011$.

27. Jianwen Zhao, Liangzhuan Wu and Jinfang Zhi, J Mater. Chern, vol. 18, pp. 2459-2465, 2008.

28. B. Gu, C. Xu, C. Yang, S. Liu, M. Wang. Biosens. Bioelectron, vol. 26 pp. 2720 - 2723, 2011.

29. A Fulati, S. M.U. Ali, M. H. Asif, N.u. H. Alvi, M. Willander, C. Brannmark, P. Stral-fors, S. 1. B6rjesson, F. Elinder, B. Danelsson. Chern, vol. 150, pp. 673, 2010.

30. Van Oss C.J, Interfacial Forces in Aqueous Media, second ed, CRC Press, New York, 2006.

31. T. Young, Philos. Trans. R. Soc. Lond. 95, 65, 1805.

32. C.J. van Oss, M.K. Chaudhury, R.J. Good, Chem. Rev. 88, 927, 1988.

33. M. Morra, C. Cassinelli . J Biomater Sci Polymer Edn 9: 55-74, 1997.

34. Van Oss CJ, Curr. Opin. Coll. Interf. Sci. 2: 503-512, 1997.

35. Busscher, H. J., Weerkamp, A.H., van der Mei, H.C., van Pelt, A.W.J., de Jong, H.P. and, Arends J., Measurement of the Surface Free Energy of Bacterial Cell Surfaces and its Relevance for Adhesion. Applied and Environmental Microbiology 48(5):980-983, 1984.

36. Van Loosdrecht, M. C. M., J. Lyklema, W. Norde, and A.J.B. Zehnder. Bacterial adhesion: A physochemical approach. Microbial Ecology 17):1-15, 1989.

37. Sawai, J. Microbiol. Methods vol. 54, pp. 177-182, 2003

38. Taylor E, Webster TJ. Int J Nanomedicine. 6:1463-1473, 2011.

39. Sawai J, Kawada E, Kanou F. J Chem Eng Jpn. 29(4):627-633, 1996.

40. Touati D. Arch Biochem Biophys. 373(1):1-6, 2000. 